\title{
CALCULATION OF TREATMENT OF LOOSE BULKY MATERIALS WITH OZONE-CONTAINING GAS
}

\author{
Aleksandr Alekseevich Simonov \\ Candidate of Chemical Sciences, Senior Researcher, Research Institute of Ion-Plasma and Laser Technologies, Tashkent,
} Uzbekistan

Mukhammadjon Parpievich Parpiev

Candidate of Technical Sciences, Associate Professor, Department of Standardization and Certification of Agricultural Products, Tashkent State Agrarian University, Tashkent, Uzbekistan

Aleksey Ivanovich Kamardin

Candidate of Physico-Mathematical Sciences, Senior Researcher, Research Institute of Ion-Plasma and Laser Technologies, Tashkent, Uzbekistan

\section{Bakhtiyor Abdulkhamidovich Khaydarov}

PhD, Associate Professor, Department of Standardization and Certification of Agricultural Products, Tashkent State

\author{
Agrarian University, Tashkent, Uzbekistan
}

DOI: https://doi.org/10.36713/epra3882

\begin{abstract}
Particularity of treatment of loose bulky materials with gas was analyzed, calculated loss of pressure under their gas treatment. It was ascertained that porosity (pore) of such objects as a layer for seeds of farming crops constitutes approximately 0,4 by capacity. Recommendations were presented on the construction of equipment's and peculiarity of treatment of layers for seeds and fruit-vegetable products with ozone.

KEYWORDS: fruit-vegetable products, ozone-containing gas, loose bulky materials, porosity.
\end{abstract}

\section{INTRODUCTION}

Modeling and problem solving on the treatment of various objects with gas require the use of knowledge in a specific field involving certain assumptions, mathematical modeling and numerical methods of its solution $[1,2,3]$. In this case the question is about the modeling of processing of seeds and fruit elements of agricultural products, placed in fixed hard content with a particular flow of ozone-containing gas (for example, ozone-aerial or ozone- oxygen mixture). Wide spread of interaction of gas flow and granular layer in the technics of processes found a considerable attention towards this phenomenon in most fields of science and technics [4, $5,6,7]$.

\section{MAIN PART}

Granular layer material always occupies more space than compact pieces of solid substance from which granular is prepared at the same mass. This is due to appearance of intergranular space in the layer. It is also observed in case of filling the space with special grain or green staff. So far as grain objects can be of various forms (grain, pyramids, balls), or the ditches formed with pores in the layers of these materials (objects), they have quite complex configuration.

Therefore, separate items of layer flow simultaneously at the movement of gas through fixed grain layers of the flow and move in the ditches of complex form. The share of vacuum of free volume or 
porosity of material or layer $(\varepsilon)$ is found to be the ratio of free volume of vacuum $\left(\mathrm{V}_{\mathrm{o}}\right)$ to total volume of material $(\mathrm{V})$, that is, $=\frac{V_{0}}{V}$. Actually the forms of seeds and fruits differ, however they can be conditionally presented with simple spatial figures - balls, cylinders, pyramids, ellipsoid gyration. Any spatial figure of grain may modify to ball-shaped form keeping its volume and mass. Ball (sphere) has conditional diameter $\left(\mathrm{d}_{\mathrm{y}}\right)$, which can, for example, coincide with the average compound size of grain or fruit independently from primary form.

Apparently, most part of seeds effectually are of ellipsoid form, particularly gyration ellipsoids, and they produce the samples of their diameters in two coordinations, and also the length which provides the importance of semi-axes (a, b) and length (c). The volume of such figure makes $\frac{4 \pi a b c}{3}$. In the equality of all diameters the formulae corresponds to ball volume. For conducting numerical calculations, it is assumed that farming objects (seeds and fruits) under the treatment, may have geometrical figure, close to sphere with conditional diameter $\left(\mathrm{d}_{\mathrm{y}}\right)$ and are arranged in hard technological volume, for example, in cylinder which has inserting and exiting tube.

Picture 1 illustrates the variant of equipment flowchart for technological treatment (blow) of agricultural objects loaded in working capacity with ozone-containing gas.

Equipment of such type with fixed layer of object under ozone treatment differs with maximal simplicity and efficiency. Therefore, objects don't experience mechanical impact of motion and interfusion. Perhaps there seems to be a blow by ozone-containing gas which is not only low, but also right from the equipment. It is also possible the use of not only high-pressure to purge, but also reduced pressure at the aspiration of gas through tubes, as well as, simultaneous impact of these factors and periodical change in the direction of blow. Reduced pressure also can be possible for hard construction with reinforced chamber wall till the sequence count of $20-50 \mathrm{~mm} \mathrm{Hg}$ in the use of vacuum pipe and also other equipments which reduce atmospheric pressure.
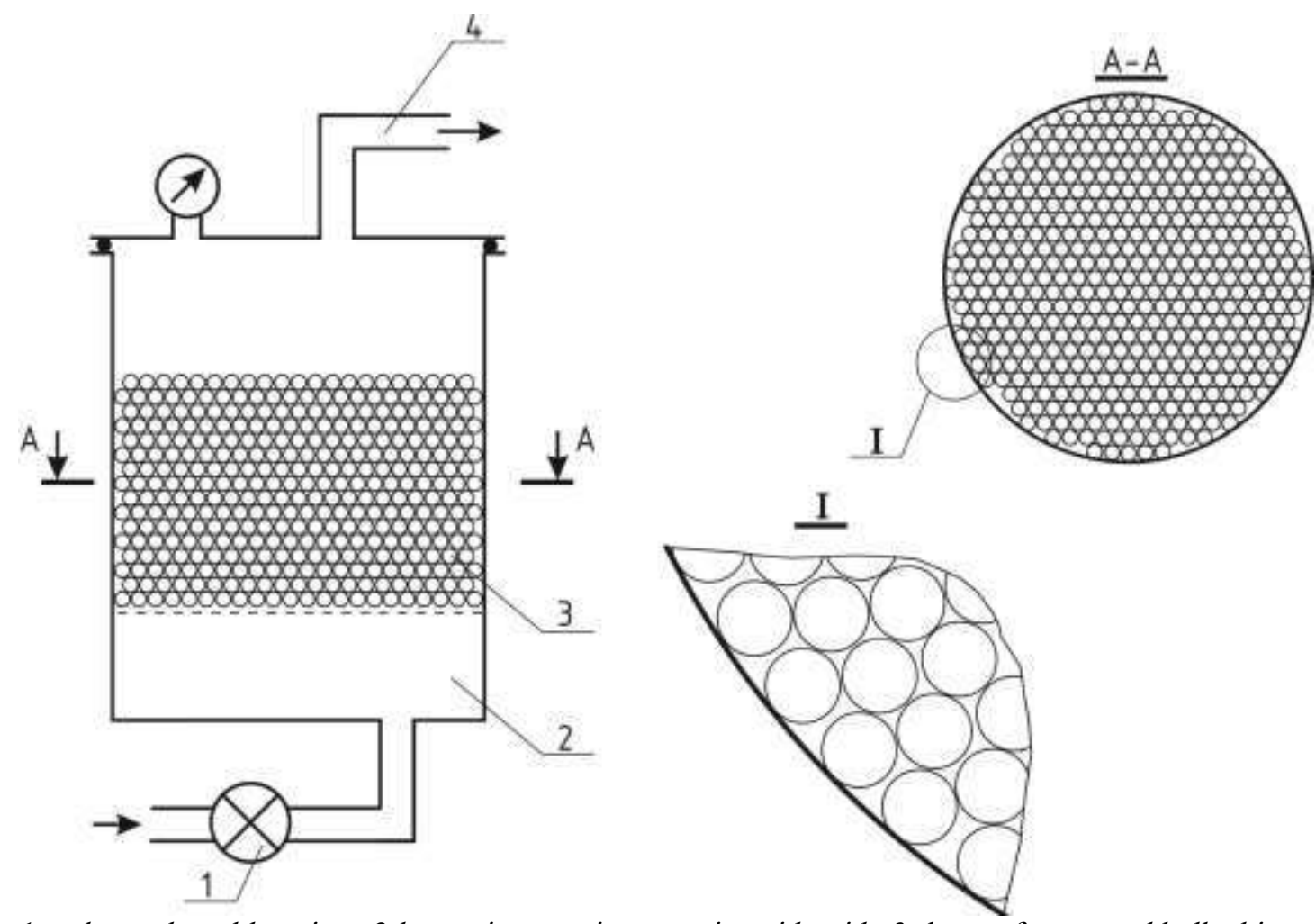

1- valve and gas blowpipe; 2-hermetic operating capacity with grid; 3-layer of processed bulk objects, 4-upper flange with tube.

Figure 1, 2. Scheme of equipment for the treatment of objects with ozone-containing gas

Practical interest requires investigation on the porosity of specific objects of agriculture in an effective volume [8-12]. The investigation on the issue of real density of packaging of such objects as balls has already launched. If to fill volume without joggle, so that balls are located at random, experimentally observed the next packaging density relationship $\mathrm{Y}$ out of the number of balls:

$$
\gamma_{1}=\frac{0,6-0,37}{\sqrt[3]{N}}(1)
$$

where $N$ - the whole number of balls in volume.

The picture of formation of grain layer gets complicated, if to consider polyfractional layer when small sized objects (fine fraction) are disposed in vacuum with definite possibility. Dominating fractions are likely to be small objects while large ones dispose between them in the form of inclusion not reducing vacuum volume. Different sized fruits can be example 
for this, also grain mixtures, polydisperse mixtures of some food products, biogranules and other objects. The investigations were conducted on porosity and other parameters of seeds and fruits in order to evaluate actually porosity of real objects (seeds and fruits) under processing.

For estimation volume measurements were used with filled objects of treatment and the volume of water which fill the vacuum (measurement glass up to 800 $\mathrm{ml}$ ). Testing objects were placed in measuring glasses that were positioned on the scales for weighing improved accuracy $( \pm 0,1 \mathrm{~g})$ of the type "OHAUS". The quantity of seeds and fruits, their weight and occupied volume, and also water mass (density $1 \mathrm{~g} / \mathrm{cm}^{3}$ ) which filled the volume of tested objects were weighed accurately. The porosity of grain layer was defined according to the results of measurement. In the $2^{\text {nd }}$ picture were presented the photos of the process of measurement on porosity of different seeds and small fruits.

Table

Parameters of porosity of the layer of plant seeds and fruits

\begin{tabular}{|l|c|c|c|}
\hline \multicolumn{1}{|c|}{ Plant seeds } & $\begin{array}{c}\text { Weight of 1000 } \\
\text { pcs of seeds, } \mathbf{g}\end{array}$ & $\begin{array}{c}\text { Porosity, } \\
\mathbf{V}_{\mathbf{o}} / \mathbf{V}_{\text {total }}\end{array}$ & Comments \\
\hline Dry dog-rose fruits & $1340-1380$ & $0,41-0,43$ & - \\
\hline Cotton plant & $100-110$ & $0,39-0,41$ & - \\
\hline Rice long-grain & $23-24$ & $0,42-0,43$ & Type Alanga \\
\hline Peas & $432-437$ & $0,39-0,40$ & - \\
\hline Lentil & $30-31$ & $0,37-0,38$ & Absorbs water \\
\hline
\end{tabular}

It was observed in this and other measurements that regardless the form and size of seeds and fruits, the porosity of such objects actually constitutes $0,4 \pm 0,02$ as a rule, at a usual load in volume.

It is necessary to use the following acquiescence for evaluation of aerodynamic resistance of grain layer (head loss of gas): grain layer is smooth by all volume, ozone-containing gas is available in favorable condition and its parameters are close to the parameters of air (pressure 1 atmosphere, i.e, around $10^{5} \mathrm{pa}$ ), gas mixture density corresponds to air density $\rho=1,3 \mathrm{~kg} / \mathrm{m}^{3}$, coefficient of dynamic viscidity of air $\mu$ makes $1,8 \cdot 10^{-5}$ $\mathrm{pa} \cdot \mathrm{s})$.

In order to define arbitrary value of Raynold amount $\mathrm{Re}$, the formulae is important which accounts both enumerated relations. Universal semirational formulae of Ergan [13] is used practically for the determination of resistance of grain layer of ball parts in unlimited interval of Re value:

$$
\Delta P=\left[150 \cdot \frac{\mu w\left(1-\varepsilon^{2}\right)}{d_{y}^{2} \varepsilon^{3}}+1,75 \cdot \frac{\rho w^{2}(1-\varepsilon)}{d_{y} \varepsilon^{3}}\right] H
$$

where,

$\Delta P$ - hydraulic layer resistance, pa; $H$ - the height of the layer of bulky material, $\mathrm{m} ; \quad W-$ speed of gas feeding, $\mathrm{m} / \mathrm{s} ; d_{y}$ - conditional diameter of the part, $\mathrm{m}$; $\mu-$ coefficient of dynamic viscidity of gas, $\mathrm{pa} \cdot \mathrm{s} ; \varepsilon-$ porosity of fixed layer.

The $3^{\text {rd }}$ picture on empiric formulae Ergan illustrates calculated relations of layer resistance of bulky material with $1 \mathrm{~m}$ thickness from the speed of ozone-containing gas for different condition.

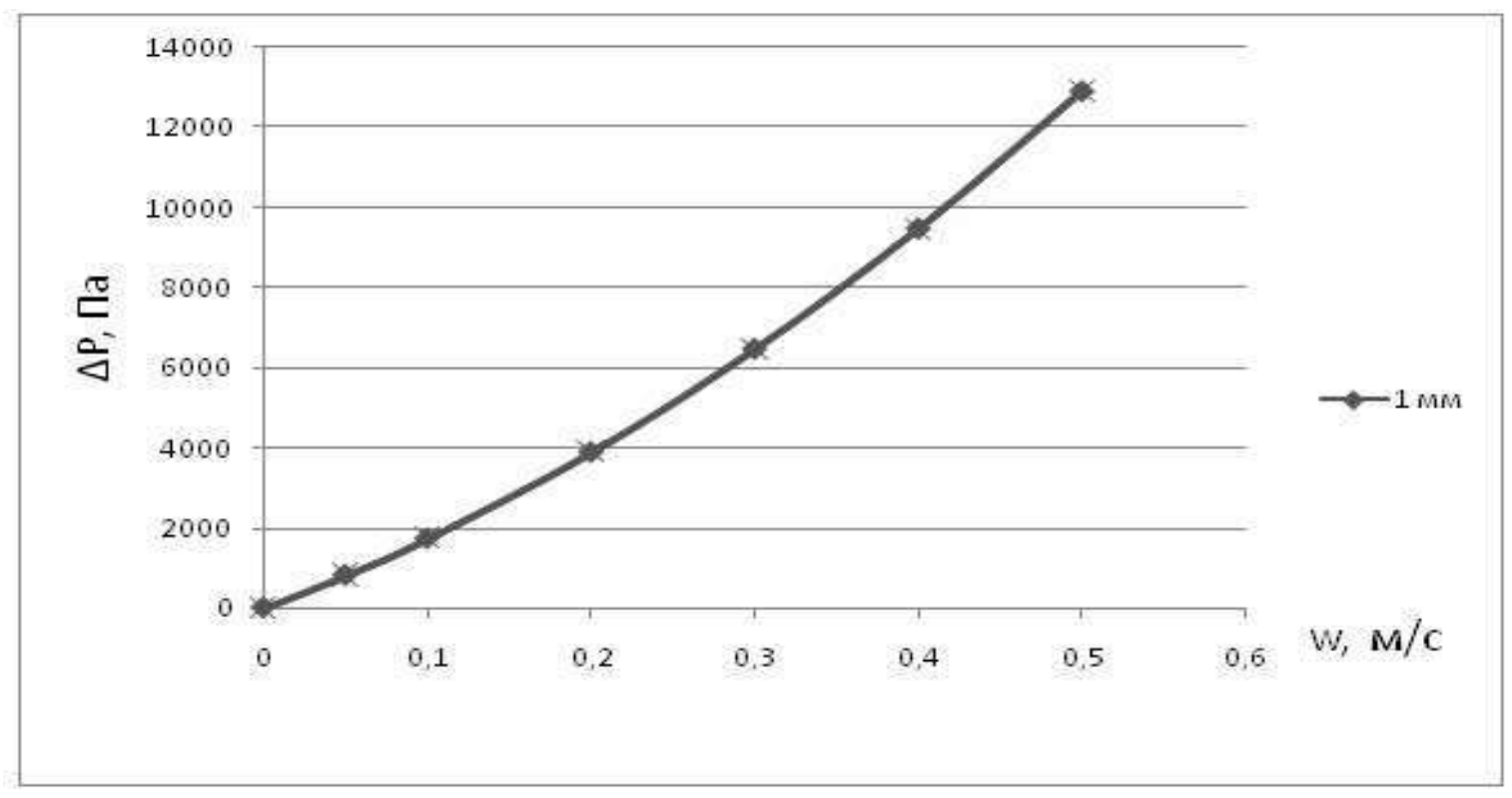

Figure 3. Relation of head loss in the layer from the speed of ozone-containing gas 
Calculations showed that for a real condition of treatment of such agricultural products like seeds and fruits of any plant with ozone, high pressure of ozonecontaining gas is not required. Small objects (order 100$200 \mathrm{mkm}$ and less) can be an exception, for which head loss of gas is increased by 1-2 atmosphere. Dominant influence on gas permeability of the fixed layer has a conditional diameter of processed objects.

The possible variant of the treatment of seeds and other agricultural objects can be ozone-containing gas feeding through the tube in the volume. In this case, hard walls of effective volume are likely to lack. For example, the treatment of the seeds in drove, open container, bags. Ozone-containing gas is distributed from tube outlet to all directions in that case by processing favorable spherical region.

Figure 4 shows possible variant of distribution of ozone-containing gas with interpenetration of treatment area. Steady treatment is available with ozone on all effective volumes at optimal hole location and number of tubes.

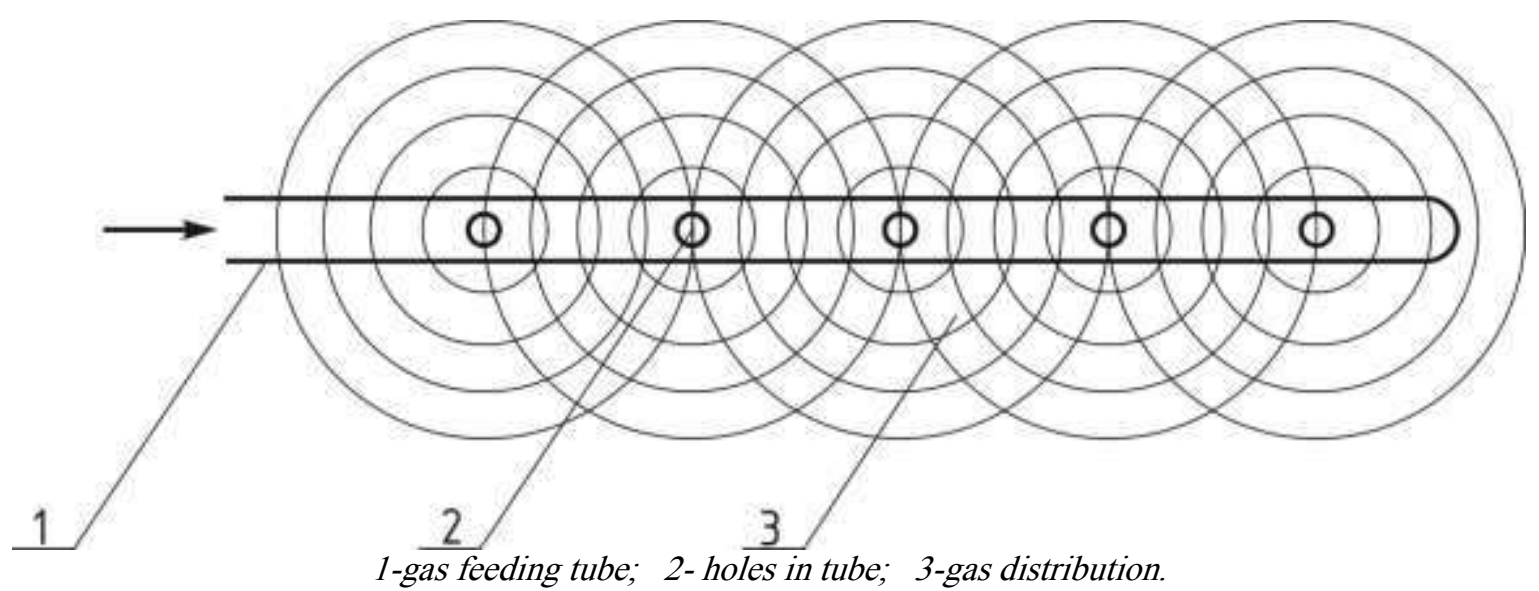

Figure 4. Distribution of ozone-containing gas from the tubes of effective volume

Ozone-containing gas occupies spherical volume with $\mathrm{R}(\mathrm{m})$ radius at ozone-containing gas feeding with $\mathrm{U}\left(\mathrm{m}^{3} / \mathrm{s}\right)$ power in processing volume during the time $\mathrm{t}$ (s) in accordance with simple relation: $\frac{4 \pi \varepsilon R^{3}}{3}=v t$ (including filling of processed volume and porosity with objects $\varepsilon$ ). Thereby, after the treatment during $t$ period, ozone-containing gas occupies spherical volume with effective radius:

$$
R=\sqrt[3]{\frac{3 v t}{4 \pi \varepsilon}}(3)
$$

It is should be noted that at ozone-containing gas feeding through tubes in effective volume the period of half-disintegration of ozone ( $\mathrm{T}$ ) in real condition may constitute $5 \div 15$ minutes. So, a fundamental unbalance of treatment of objects occurs due to concentration rate of rise from the point of ozone distribution to periphery. While calculating treatment it should be taken into consideration that the time of transfer $(\mathrm{t})$ of ozonecontaining gas through the given layer of bulky objects with density $(\lambda)$ mustn't exceed critical value $t_{\mathrm{kp}}$.

If specify admissible uniformity (fall) of concentration of ozone within $25 \%$, then the time for reaching to the fall in concentration can be estimated according to well-known exponential relation:

$$
C(t)=C_{0} \exp \left(-\frac{0,693 t}{\tau}\right)(4),
$$

where $C_{0^{-}}$ozone concentration in entrance point, $\left(\mathrm{mg} / \mathrm{m}^{3}\right), C(\mathrm{t})$ - ozone concentration by time $\mathrm{t},\left(\mathrm{mg} / \mathrm{m}^{3}\right)$, $T$-period of half-disintegration of ozone, s. In formulae (4), $\ln 2=0,693147 \approx 0,693$. Simple calculation shows that concentration fall $\mathrm{C}(\mathrm{t})$ to the degree of $0,75 \mathrm{C}_{\mathrm{o}}$ starts at the value of indications of minus exponents 0,285 , i.e, at $\mathrm{t}=0,41 \mathrm{~T}(\mathrm{~s})$. Thereby, critical time $\left(\mathrm{t}_{\mathrm{kp}}\right)$ of the movement of ozone-containing gas, for example, 10 minutes for half-disintegration of ozone mustn't exceed 4 minutes.

This requires a certain correlation of processed effective volume and a speed of ozone-containing gas inflow Q $\left(\mathrm{m}^{3} / \mathrm{s}\right)$. For example, ozone-containing gas feeding speed Q less than $\frac{\pi D^{2} H \varepsilon}{0,41 \tau}$ is required for cylindrical construction of operating chamber (picture 1) with diameter $\mathrm{D}(\mathrm{m})$ and with object layer density $\mathrm{H}$ (m) at full load and porosity of layer $\varepsilon$, i.e, $Q \geq \frac{7,66 D^{2} H \varepsilon}{\tau}$. At the blow of object layer in operating chamber alternately from above and below of layer density, actual increase can be twice.

For example, for an operating chamber with around 1001 volume (diameter $0,5 \mathrm{~m}$, height $0,5 \mathrm{~m}$ ) at the porosity of object of $\varepsilon=0,4$ and in the period of half-disintegration of ozone of 10 minutes $(600 \mathrm{~s})$, a speed of ozone-containing gas inflow of $\geq 0,51 / \mathrm{s}$ is required for one-sided blow of volume. In case of gas feeding through the tube with zone perforation of steady treatment (with concentration fall of $20-25 \%$ ), the sphere is likely to be formed. Diameter of such sphere corresponds to the volume of ozone-containing gas which spreads within the time $0,4 \mathrm{~T}$. On the base of the coefficient of porosity the diameter of sphere increases by $15-20 \%$ more. Accordingly, the position of gas feeding tubes and perforation are to provide a certain 
mutual interpenetration of sphere (picture 4) that guarantees the current uniformity of ozone effect.

It should be emphasized that a real process of effect of ozone starts with ozone-containing gas flushing to the parts of processed volume or initial region of grain layer from the point of ozone entry. This region appears under the ozone effect much longer time while ozone-containing gas flushing occurs in the parts of processed layer. This time of effect constitutes approximately $(0,4 \div 0,5) \mathrm{T}$ which should be considered in calculations.

\section{REFERENCES}

1. Gaidishev I.P. (2004). Solution of scientific and engineering issues with Excel, $V B A$ and $C / C++/$ means I.P. Gaidishev. - SPb.: BHB - Petersburg, 512 p.

2. Koshelev V.E. (2008). Excel 2007. Effective use / V.E. Koshelev. Moscow: Binom. Laboratory of knowledge, 544 p.

3. Below V.V., Obratsov I.V., Ivanov V.K., Konoplev E.H. (2015). Computer implementation are the solution of scientific-technical and educational issues. Tver: TvGTU, $102 p$.

4. Laptev A.G. (2007). Models of limitary layer and calculation of heat-mass-exchange processes Kazan: Publish. Kazakhstan, 500 p.

5. Oran E., Boris J. (1990). Numerical modeling of reactive flow. Trans. from English. Moscow: Mir.

6. Kasatkin A. G. (2005). Main processes and equipments for chemical technology. Moscow: Alyans, $750 \mathrm{p}$.

7. Abramovich G.N. (1991). Practical gas dynamics: in $2 h$. $5^{\text {th }}$ edit., amend. and add. Moscow: Nauka, 600 p.

8. Sosna M. Kh., Meytin I. V., Zavelev E. D., Semenov V. P. (1976). Calculation of mean porosity of grain layer. Chemical manufacture. №7. pp. 557-558.

9. Pushnov A. S., Naumov Yu. B., Kagan A. M., Gelperin I. I., Pishyk L.Ya. (1986). The impact of structure for packaging grain in ball forms in cylindrical equipments at gas distribution. Heat power industry. № 8. pp. 70-72.

10. Sloen M.J.A. Ball Packing. http://wrwwegamath.narod.ru/Nquant/Spheres.htm

11. Rojehrs K. (1968). Packaging and layering. Moscow: Mir.

12. Mueller G. E. (2010). Radial porosity in packed beds of spheres. Powder Technology. №203, pp. 626-633.

13. Shishkin A.S., Shishkin S.F. (2015). Examples of calculation of aerodynamic processes of processing of bulky materials in Excel. Ekaterinburg, UrFU, pp. 271-275.

\section{CONCLUSION}

The treatment of layers of bulky materials with ozone-containing gas, such as plant seeds and fruits, should consider porosity of such objects which as a rule constitutes about 0,4 head loss of gas that defines mainly diameter of objects and correlation of processed volume with the speed of ozone-containing gas feeding. It is advisable to use hard cylindrical effective volume with alternate gas feeding from above and below parts. 